\title{
Erratum to: Comparison of in vitro test systems using bacterial and mammalian cells for genotoxicity assessment within the health-related indication value (HRIV) concept
}

\author{
Eva-Maria Prantl ${ }^{1,2}$ - Meike Kramer ${ }^{1}$ - Carsten K. Schmidt ${ }^{1}$ - Martina Knauer ${ }^{3}$. \\ Stefan Gartiser ${ }^{3}$ • Aliaksandra Shuliakevich ${ }^{2}$ - Julia Milas ${ }^{2}$ - Hansruedi Glatt ${ }^{4}$. \\ Walter Meinl $^{4} \cdot$ Henner Hollert ${ }^{2}$
}

Published online: 27 January 2017

(C) Springer-Verlag Berlin Heidelberg 2017

Erratum to: Environ Sci Pollut Res

DOI 10.1007/s11356-016-8166-Z

The names were interchanged in the original publication of this paper.

The original article was corrected.

Eva-Maria Prantl

eva-maria.prantl@gmx.de

1 Water Laboratory, RheinEnergie AG, Parkgürtel 24, 50823 Köln, Germany

2 Department of Ecosystem Analysis, Institute for Environmental Research, ABBt - Aachen Biology and Biotechnology, RWTH Aachen University, Worringerweg 1, 52074 Aachen, Germany

3 Hydrotox GmbH, Bötzinger Straße 29, 79111 Freiburg im Breisgau, Germany

4 Department of Nutritional Toxicology, German Institute of Human Nutrition (DIfE) Potsdam-Rehbruecke, Arthur-Scheunert-Allee 114-116, 14558 Nuthetal, Germany 